\title{
Elementos da televisão clássica no SBT: análise estilística do Domingo Legal ${ }^{1}$
}

\author{
Elements of classical television in SBT: stylistic analysis of Domingo Legal \\ Elementos de la televisión clásica en el SBT: análisis estilístico de Domingo \\ Legal \\ João Paulo Hergesel ${ }^{2}$ \\ Rogério Ferraraz ${ }^{3}$
}

\section{Resumo}

O Domingo Legal é um programa de auditório do SBT que está no ar desde 1993 conquistando índices de audiência plausíveis para a emissora. Apresentada por Celso Portiolli, a atração sofreu uma forte turbulência em 2015, com o encurtamento de sua duração e o fortalecimento dos concorrentes; no entanto, apostando em quadros de entretenimento familiar e nas disputas entre equipes, o programa se manteve acima da média de audiência do SBT. Com o objetivo de descobrir se os elementos que conduzem a atmosfera afetiva dessa narrativa em processo condizem com a proposta de análise para as narrativas ficcionais da chamada televisão clássica, este artigo analisa, pela visão dos estudos estilísticos, um episódio do Passa ou Repassa, quadro presente em quase todas as semanas do respectivo ano.

\begin{tabular}{|c|c|}
\hline & Acesse este artigo online \\
\hline \multirow{2}{*}{ 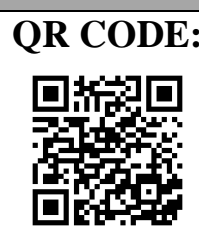 } & $\begin{array}{l}\text { Website: } \\
\text { http://www.revistas.ufg.br/index.php/ci }\end{array}$ \\
\hline & $\begin{array}{l}\text { DOI: } \\
\text { http://dx.doi.org/10.5216/ci.v20i3.46173 }\end{array}$ \\
\hline
\end{tabular}
heavy turbulence in 2015, with the shortening of the duration and the strengthening of competitors; however, betting on family entertainment and on challenges between teams, the program is kept above the SBT's ratings medium. In order to discover if the elements which conduce the afective atmosphere from this narrative in process match the purpose to analyze storytelling from the called classical television, this paper analyses, through the stylistic studies, an episode from Passa ou Repassa (Dare or Double Dare), segment present in almost all weeks in the respective year.

Keywords: Audiovisual. Television. Media narratives. Stylistics. SBT.

\footnotetext{
${ }^{1}$ Texto derivado de trabalho apresentado no XVIII Congresso de Ciências da Comunicação na Região CentroOeste, realizado de 19 a 21 de maio de 2016, e publicado nos anais do evento com o título "SBT em busca de um Domingo Legal".

${ }^{2}$ Doutorando em Comunicação pela Universidade Anhembi Morumbi (UAM) e bolsista da Coordenação de Aperfeiçoamento de Pessoal de Nível Superior (PROSUP/Capes). Membro dos Grupos de Pesquisa Inovações e Rupturas na Ficção Televisiva Brasileira (UAM/CNPq) e Narrativas Midiáticas (Uniso/CNPq). Contato: jp_hergesel@hotmail.com.

${ }^{3}$ Doutor em Comunicação e Semiótica (PUC-SP), mestre em Multimeios (Unicamp) e graduado em Jornalismo (UNESP-Bauru). Foi pesquisador visitante na UCLA Los Angeles, com bolsa de doutorado-sanduíche (Capes). É professor do Programa de Pós-Graduação em Comunicação da Universidade Anhembi Morumbi (UAM). Contato: rferraraz@anhembi.br.
}

Comun. \& Inf., Goiânia, GO, v. 20, n. 3, p.113-131, out./dez. 2017 


\section{Resumen}

Domingo Legal es un programa de auditório del SBT que está em el aire desde 1993 conquistando índices de audiência plausibles para la emisora. Presentada por Celso Portiolli, la atracción sufrió una flerte turbulência en 2015, con el acortamiento de su duración y el fortalecimiento de los competidores; sin embargo, apostando encuadros de entretenimiento familiar y em las disputas entre equipos, el programa se mantuvo por encima del promedio de audiência del SBT. Con el objetivo de descubrir si los elementos que conducen la atmósfera afectiva de esa narrativa em processo concuerdan com la propuesta de análisis para las narrativas ficcionales de la llamada televisión clásica, este artículo analiza, por la visión de los estudios estilísticos, un episodio del Passa o Repassa, cuadro presente em casi todas las semanas del año respectivo.

Palabras clabe: Audiovisual. Televisión. Narrativas mediáticas. Estilística. SBT.

\section{OBSERVAÇÕES INICIAIS}

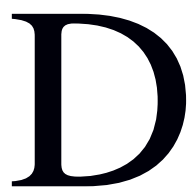
inamismo e diversão são as características que qualificam o Domingo Legal, conforme o Sistema Brasileiro de Televisão (SBT) informa à imprensa internacional: "Domingo Legal reúne o melhor da música, do noticiário e do entretenimento em um formato dinâmico e divertido, geralmente com a participação de celebridades renomadas do Brasil e do resto do mundo" (SBT, 2016, p. 16).

No ar desde 17 de janeiro de 1993, a atração foi criada por Roberto Manzoni "Magrão" e dirigida por ele mesmo até 26 de abril de 2016, quando pediu um período sabático (FALCHETI, 2016). O programa, cuja direção geral foi assumida por Rubens Gargalaca Jr. desde maio do respectivo ano, deixou sua marca na história da televisão brasileira ao atingir o número de mil programas em 10 de março de 2013 (DOMINGO, 2016).

Apresentado por Celso Portiolli (inicialmente era comandado por Gugu Liberato, hoje contratado da RecordTV), o programa teve o Viva a Noite, musical dos anos 1980, como fonte de inspiração. Nas palavras do criador: "Nossa missão era desenvolver uma novidade para ser gravada no sábado e entrar no ar no domingo. O problema é que Silvio Santos nos avisou dessa tarefa na quarta-feira! [...] o que fizemos foi uma versão do Viva a Noite [...]" (MANZONI, 2005, p. 87).

O Domingo Legal surgiu dentro do Programa Silvio Santos como uma atração focada nos game shows. Quadros como Cidade contra Cidade, Passa ou Repassa, Corrida Maluca, Prova do Tato, Prova do Bicho, Banheira do Gugu marcaram os domingos dos anos 1990 no SBT e atingiram picos de 47 pontos de audiência no IBOPE - quando da cobertura da morte dos membros dos Mamonas Assassinas, banda sempre presente no programa. Conforme registros da imprensa: 
Com vídeos relembrando a trajetória da banda, informantes ao vivo no palco e também no local do acidente e até a presença da Mãe Dinah que disse ter previsto a tragédia, o dominical, que dedicou praticamente toda a sua edição à cobertura da morte do grupo, registrou nada mais nada menos que 37 pontos de média e 47 de pico. No horário, a Globo registrou apenas 13 pontos. A audiência foi explosiva, feito que é marcado até hoje no SBT, pois os índices registrados naquele domingo, estão entre as maiores audiências da história da emissora (SANTOS, 2014, p. 1).

Uma situação marcante e frequentemente relembrada pela imprensa - e revisitada inclusive na esfera acadêmica - foi o ocorrido em 2003, quando Gugu supostamente entrevistou membros do PCC (Primeiro Comando Central), facção criminosa que age em São Paulo. Após descoberta a farsa e interrogatórios na Delegacia de Polícia, a Justiça proibiu a exibição do Domingo Legal por algumas semanas (FOLHA, 2003), fazendo com que o SBT reprisasse programas exibidos há algum tempo ou até mesmo engavetados.

Após esse episódio, o programa caiu no descrédito e passou a apelar para o sensacionalismo, explorando o assistencialismo e o realismo da classe baixa, a fim de recuperar sua audiência. Criaram-se, assim, quadros como De volta pra minha terra, Sentindo na pele, Aconteceu comigo, Construindo um Sonho, além de constantes interações jornalísticas. O sucesso, no entanto, não foi recuperado (MATTOS, 2007) - e a média geral de audiência do programa em 2006, por exemplo, foi de apenas 12 pontos.

Com a saída de Gugu e a entrada de Celso Portiolli, em 12 de julho de 2009, o programa sofreu diversas modificações, especialmente em seu horário de exibição. Sendo exibido em 2017 (ano de fechamento deste artigo) das $13 \mathrm{~h}$ às $15 \mathrm{~h}$, o programa mescla o que experimentou ao longo de seus anos: desde competições entre equipes e apresentações musicais a recortes de jornalismo e produções de caráter social. Ainda que não conquiste mais os louros do passado, sustenta-se sempre acima da média de audiência do SBT, que é de 5 pontos no IBOPE.

\subsection{Foco e escopo}

Vê-se que, mesmo após 20 anos no ar, o formato sempre busca a renovação, substituindo seus quadros e reformulando os de maior sucesso. Em 2015, o Domingo Legal sofreu fortes turbulências, como a perda de duas horas de duração - devido à estreia do Mundo Disney (programa diário, com duração de duas horas, que exibe séries, desenhos e filmes produzidos pelo Disney Channel) aos domingos - e o fortalecimento do concorrente Domingo Show (programa de variedades exibido pela RecordTV, que mescla entretenimento, jornalismo e assistencialismo), o que abalou sua audiência consideravelmente (REVISTA, 2015). Ainda 
assim, o programa encerrou o ano com várias vitórias sobre a RecordTV e alguns momentos à frente da Rede Globo (PECCOLI, 2015a).

Dentre os quadros que compuseram as semanas de 2015, estão:

a. Passa ou Repassa: jogo de perguntas e respostas entre equipes, as quais têm três alternativas: responder, passar/repassar ou pagar (realizar uma prova). É popularmente conhecido pela etapa do Torta na Cara, em que o participante que acertar a resposta lambuza o rosto do adversário com uma torta de chantili;

b. De quem é essa mansão?:Com os humoristas Pedro Manso e Marlei Cevada, Celso Portiolli visita a mansão de pessoas famosas e tenta descobrir quem é o proprietário do imóvel;

c. Construindo um Sonho: pessoas escrevem cartas pedindo a reforma de suas casas e, por meio de uma surpresa, Celso Portiolli se apresenta aos contemplados;

d. Celso Visita: Celso Portiolli faz visitas a celebridades - brasileiras e do exterior - para entrevistá-las em sua casa ou em seu local de trabalho;

e. As aventuras de Celso Portiolli: Celso Portiolli viaja o mundo e registra seus passeios a parques de diversões, lojas temáticas, estúdios de cinema ou empresas renomadas;

f. Maisa: a jovem Maisa Silva faz reportagens de entretenimento, geralmente registrando o making of de novelas e filmes, nacionais e internacionais;

g. A Princesa e o Plebeu: um artista do gênero masculino - na temporada de 2015, houve duas participações com o cantor Biel e uma com o próprio Celso Portiolli - leva uma fã para fazer compras e se divertir, geralmente, em algum ponto turístico ou parque de diversão

h. Afunda ou Boia: jogo que consiste em os participantes acertarem se o objeto a ser colocado no aquário tende a afundar ou boiar;

i. Em quem você dá uma tortada?: artistas convidados ganham tortas de chantili e, ao serem reveladas fotos de outras celebridades, decidem se elas são aprazíveis ou se merecem ser lambuzadas.

Também estiveram presentes variedades gravadas em externa e no palco, como depoimentos, atrações musicais e apresentações de talento. Não se descarta ainda a notória quantidade de merchandisings, que invadem a narrativa construída domingo a domingo. Em uma observação analítico-estatística acerca desses produtos, elaborou-se uma tabela para que ficasse mais visível a incursão no programa, ao longo de 2015, dos quadros mencionados:

Tabela 1 - Quantidade de vezes em que os quadros do "Domingo Legal" foram apresentados em 2015 


\begin{tabular}{ll}
\hline \multicolumn{1}{c}{ NOME DO QUADRO } & \multicolumn{1}{c}{ EXIBIÇÕES EM 2015 } \\
\hline Passa ou Repassa & 51 domingos \\
\hline De quem é essa mansão? & 11 domingos \\
\hline Construindo um Sonho & 10 domingos \\
\hline Celso Visita & 6 domingos \\
\hline As aventuras de Celso Portiolli & 4 domingos \\
\hline Maisa & 4 domingos \\
\hline A Princesa e o Plebeu & 3 domingos \\
\hline Afunda ou Boia & 3 domingos \\
\hline Em quem você dá uma tortada? & 2 domingos \\
\hline Gravações em externa & 18 produções \\
\hline Atrações no palco & 23 produções \\
\hline Total de programas analisados & $\mathbf{5 2 ~ d o m i n g o s ~}$ \\
\hline
\end{tabular}

Fonte: Elaboração própria

Consideram-se, como "gravações em externa", depoimentos, reportagens e demais matérias de cunho jornalístico gravadas fora dos estúdios do SBT e exibidas como complemento para o programa. Como "atrações no palco", consideram-se eventos musicais, apresentações de talentos, entrevistas com artistas convidados, brincadeiras com a plateia, dentre outras possibilidades de utilização do espaço cênico ao vivo. Optou-se, ainda, por nomear os dois últimos itens da coluna à direita como "produções" devido ao fato se serem possíveis, para estes casos, dois (ou mais) conteúdos num mesmo domingo.

Haja vista que o Passa ou Repassa predominou enquanto quadro do Domingo Legal não indo ao ar somente um domingo do ano, em 25 de outubro, quando o programa se concentrou em homenagear a cantora mexicana Lucero ${ }^{4}$ - optou-se por analisá-lo enquanto amostra do que se apresenta no geral. Acredita-se ainda que, por ser ao vivo, realizado no palco, contar com a participação do auditório e ocupar a maior parte da duração de cada programa (quando este não se dedica exclusivamente ao quadro), o objeto cumpre com o dever de representar a macronarrativa. (Adendo: entende-se que os programas de variedades são macronarrativas, compostas por micronarrativas que se unem por entrelaçamento ou mera justaposição.)

\subsection{Recorte eleito}

${ }^{4}$ Lucero participa do Domingo Legal. SBT, 25 out. 2015. Disponível em: 〈https://goo.gl/jo848K>. Acesso em: 09 abr. 2016.

Comun. \& Inf., Goiânia, GO, v. 20, n. 3, p.113-131, out./dez. 2017 
O Passa ou Repassa estreou no SBT em 1987, como um quadro do Programa Silvio Santos e intitulado Passe ou Repasse. Na chamada de estreia ${ }^{5}$, entre imagens em preto e branco de Silvio Santos irreverente, o locutor anuncia: "Vamos nos divertir nesta sensacional estreia, que tem a participação direta da alegria do nosso lar, que é a criança. A criança competindo com maravilhosas brincadeiras no palco". Depois, conclui: "Vamos todos juntos, neste domingo, passar momentos de muita alegria com a estreia de Passe ou Repasse”.

Nessa fase inicial ${ }^{6}$, duas duplas de crianças (representando suas respectivas escolas), sob a animação de Silvio Santos, participavam de várias provas e, ao passo em que conseguiam concluí-las, acumulavam prêmios, que a equipe ganhadora levaria para casa. Eram em geral: jogos de tabuleiro, rádios de pilha, relógios de pulso, panelas de pressão, gravadores, máquinas de escrever, videogames e bicicletas. A atração era sustentada pelo bordão: "Quando a cabeça não pensa, o corpo padece”.

No ano seguinte, em 1988, a atração passou a ser apresentada por Gugu, ainda dentro do Programa Silvio Santos. Após 1990, o formato ganhou a brincadeira da Torta na Cara e, em 1993, passou a integrar, pela primeira vez, o programa Domingo Legal ${ }^{7}$. Em 1995, o Passa ou Repassa se tornou independente e passou a ser exibido de segunda a sexta, comandado por Angélica $^{8}$. Em 1996, no entanto, com a ida da apresentadora para a Rede Globo, o programa passou a ser conduzido por Celso Portiolli ${ }^{9}$.

Em 2000, o programa saiu do ar por decisão da direção artística da emissora, mas retornou com reprises em $2004^{10}$. Depois de alguns anos de hiato, a atração voltou como quadro do Domingo Legal em $2013^{11}$, ainda sob apresentação de Celso Portiolli. Inicialmente, o produto era feito com escolas e gravação prévia (como nos anos 1990), mantendo as mesmas provas e a mesma estrutura; no entanto, o formato foi logo adaptado para o programa ao vivo e passou a ser realizado no palco, com celebridades e, muitas vezes, entrelaçando outros quadros.

\footnotetext{
${ }^{5}$ Programa Silvio Santos | Chamadas (1987). YouTube: PEGADINHAS \& ETC - THE ORIGINAL CHANNEL!, 19 ago. 2012. Disponível em: 〈https://goo.gl/8oodAV〉. Acesso em: 12 abr. 2016.

${ }^{6}$ Passa ou Repassa com Silvio Santos. YouTube: Página do Silvio Santos, 31 ago. 2013. Disponível em: <https://goo.gl/bUZ129>. Acesso em: 12 abr. 2016.

7 Passa ou Repassa com Gugu. YouTube: Passa ou Repassa, Playlist, 5 mar. 2016. Disponível em: <https://goo.gl/2vrKGD>. Acesso em: 12 abr. 2016.

${ }^{8}$ Passa ou Repassa com Angélica. YouTube: Passa ou Repassa, Playlist, 5 mar. 2016. Disponível em: <https://goo.gl/OAl1qr>. Acesso em: 12 abr. 2016.

${ }^{9}$ Passa ou Repassa com Celso Portiolli (de 1996 a 1999). YouTube: Passa ou Repassa, Playlist, 7 mar. 2016. Disponível em:<https://goo.gl/g2WqXi>. Acesso em: 12 abr. 2016.

${ }^{10}$ Passa ou Repassa com Celso Portiolli (2000). YouTube: Passa ou Repassa, Playlist, 14 mar. 2016. Disponível em: <https://goo.gl/EiTRUa>. Acesso em: 12 abr. 2016.

${ }^{11}$ Passa ou Repassa com Celso Portiolli (2013-2016). YouTube: Passa ou Repassa, Playlist, 14 mar. 2016. Disponível em: <https://goo.gl/7xqose>. Acesso em: 12 abr. 2016.
}

Comun. \& Inf., Goiânia, GO, v. 20, n. 3, p.113-131, out./dez. 2017 
Devido ao fato de o material ser extenso - ao se considerar uma média de $1 \mathrm{~h} 30 \mathrm{~min}$ por semana em que foi ao ar, o Passa ou Repassa totalizaria mais de 76 horas de conteúdo audiovisual somente em 2015 - escolheu-se um recorte: o programa exibido em 21 de junho. Essa opção foi selecionada tendo em vista o fato de que, nesse dia, o programa atingiu a liderança em audiência em alguns momentos (PECCOLI, 2015b).

Com atores do próprio SBT, mais especificamente da novela Carrossel, duas equipes (azul e amarela) disputaram as provas de 21 de junho de 2015. No time amarelo, participaram Jean Paulo Campos, Fernanda Concon, Gustavo Daneluz e Márcia de Oliveira; no time azul, Nicholas Torres, Konstantino Atanassopolus, Ana Vitória Zimmermann e Henrique Stroeter. O quadro se iniciou às 11 horas e teve duração média de três horas, se considerados os intervalos e merchandisings.

\subsection{Objetivos e justificativa}

Kristin Thompson ficou conhecida nos estudos de Comunicação por sugerir a definição de televisão clássica (classical television) ao transferir, para a análise de programas televisivos, um olhar semelhante ao que aplicada ao cinema clássico hollywoodiano. Segundo a pesquisadora (THOMPSON, 2003, p. 19), isso ocorre porque a fórmula aplicada a esses tipos de narrativa tende a ser unificada e facilmente compreensível, cuja finalidade é prioritariamente a de entreter.

Este artigo, portanto, além de ser mais um avanço nos estudos voltados ao projeto de pesquisa que visa à análise estilística da programação contemporânea do SBT, ainda sustenta como objetivo principal investigar se o estilo presente nos filmes produzidos por Hollywood considerados cinema massivo - demonstra-se equivalente em programas nacionais, assim como Thompson detectou na televisão norte-americana.

Para além disso, busca-se descobrir se os elementos que conduzem a atmosfera afetiva dessa narrativa em processo - o Passa ou Repassa, enquanto micronarrativa, e consequentemente o Domingo Legal, enquanto macronarrativa - condizem com a proposta de análise para as narrativas ficcionais da chamada televisão clássica. Pretende-se, com isso, despetalar um produto midiático que pode, além de retratar a identidade da televisão aberta brasileira, revelar sua contribuição para as práticas sociais e culturais. Opta-se, portanto, por elaborar uma discussão sob a visão dos estudos estilísticos.

Por meio desse procedimento, testado em estudos iniciais, torna-se possível detectar a sensibilidade dispensada a essa forma de expressividade. Para os estudos televisivos em geral, 
a análise estilística auxilia a identificar as propriedades do fazer poético (quando da criação do objeto) e compreender o despertar estético (quando da apreciação do produto final). Espera-se que esse percurso possibilite detectar o impacto propiciado pelo Domingo Legal - e mais especificamente pelo Passa ou Repassa - por intermédio da visualidade, da trilha sonora e dos diálogos.

\subsection{Metodologia}

Simone Maria Rocha e Renato Luiz Pucci Junior são, hoje, duas grandes referências em estudo de estilo televisivo no Brasil. Para ele (PUCCI JR., 2014a, p. 676), estilo corresponde ao "uso sistemático e significante de técnicas do meio, em termos individuais ou de grupo". Para ela (ROCHA, 2014, p. 1087), a análise estilística ajuda a compreender "como os programas são produzidos da perspectiva dos produtores" e "permite um entendimento mais sofisticado da programação, além de uma apreciação mais nuançada de textos que são mais ambiciosos do ponto de vista estético".

Ambos têm como objeto de embasamento as ideias defendidas por David Bordwell, quanto ao estilo cinematográfico, e por Jeremy Butler, que sugere uma transição para a televisão. As análises estilísticas no audiovisual, em território nacional, no entanto, começaram a ganhar forças somente nos anos 2000, quando da tradução da bibliografia bordwelliana (PUCCI JR., 2014b, p. 2). Por ser uma proposta de análise televisiva recente em território brasileiro e carente na área da Comunicação, oferece-se, neste trabalho, um resgate de como a como a Estilística vem sendo trabalhada, partindo da Linguística até chegar ao audiovisual.

A palavra "Estilística" se deriva do latim stilus, artefato com o qual os homens antigos escreviam em tábuas enceradas exclusivamente para esse fim, resgata Nilce Sant'Anna Martins (2008, p. 17-18). Na língua portuguesa, "estilo" chegou não como uma ferramenta para a escrita (diferentemente do francês, em que "stylo" é tradução para "caneta"), mas como o conjunto de fatores que distingue uma criação, explica Cláudio Cezar Henriques (2011, p. 25-26). O estudo do estilo, portanto, não deve se limitar a uma única forma de manifestação. Conhecida até mesmo como ciência da expressão, segundo Pierre Guiraud (1970, p. 7), a Estilística se preocupa em investigar a relação entre linguagem e sensibilidade.

Tem-se em mente que os estudos estilísticos iniciaram no final do século XIX, partindo da visão que Ferdinand de Saussure (1857-1913) aplicava sobre a compreensão dos signos linguísticos, elevando a Linguística ao posto de ciência autônoma. A Estilística, no entanto, consolidou-se como disciplina somente após a contribuição de Charles Bally (1909, p. 16), 
seguidor das teorias saussureanas, para quem a função da análise estilística é investigar "a expressão dos fatos da sensibilidade por meio da linguagem e a ação dos fatos da linguagem sobre a sensibilidade".

Quase cem anos depois, muitas divergências dentro da área das Letras resultaram num escopo amplificado da Estilística, como a divisão em Descritiva e Idealista, bem como as subdivisões em Estrutural, Gerativa, Retórica, Poética, Semiótica e Estatística, como aponta José Lemos Monteiro (2005, p. 15). Nilce Sant'Anna Martins (2008, p. 39), no entanto, ao compilar as principais ideias sobre o tema, menciona que disciplina é tão somente uma e a ela cabe observar "o conhecimento dos fatos da linguagem em geral (visto que as figuras não são exclusivamente da linguagem literária) e da linguagem artisticamente elaborada em particular".

Dentro da concepção de estudos estilísticos como método analítico de diferentes modalidades linguísticas, Iuri Lotman (1993, p. 41), fazendo uma ponte com a área das Artes e da Comunicação, disserta que a Estilística é responsável por fazer brotar um efeito artístico no texto - entendendo "texto" como o registro de qualquer forma de expressão. Derivada dessa visão adotada pelo semioticista russo, Míriam Cristina Carlos Silva (2009, p. 51), ao abordar a mídia num geral, acredita que os recursos estilísticos “desperdiçam significâncias”, "aguçam os sentidos do receptor", são "signos gerando signos que geram outros signos", são "referentes gerando referentes e visando ao prazer textual".

Partindo de novos caminhos, sobretudo do formalismo estético no cinema, a Estilística chegou ao audiovisual, sucintamente deslocada da carga literária nela impregnada, mas com aplicações pertinentes relacionadas à técnica. David Bordwell (2013, p. 17), ao discutir o cinema, considera como estilo o uso expressivo das técnicas cinematográficas, englobando "mise-en-scène, enquadramento, foco, controle de valores cromáticos e outros aspectos da cinematografia, da edição e do som".

Jeremy Butler (1986, p. 55), ao oferecer uma transição do cinema para a televisão, enxerga o estilo como "a padronização das técnicas, a relação sintagmática e paradigmática de um elemento para outros elementos em um sistema textual [...] (mise-en-scène e propriedades videográficas)". Sugere-se, portanto, que essa nova abordagem para os estudos estilísticos, inteiramente da Comunicação Audiovisual, deve coexistir com o aprofundamento já oferecido pela área das Letras. Por meio da interdisciplinaridade, alçamos um nível nos estudos de Estilística como metodologia para o campo da Televisão.

\section{ANÁLISE ESTILÍSTICA DO DOMINGO LEGAL}


Diferente do que alguns pesquisadores de Comunicação acreditam, a televisão tem estilo. Rocha (2016, p. 28-29) enumera alguns equívocos cometidos ainda hoje pelos pares, como o de acreditar que: a televisão não merece o mesmo cuidado analítico dedicado ao cinema por ser somente um instrumento de transmissão; o aparelho televisor e os aspectos envolvendo sua capacidade de exibição audiovisual importam mais do que o audiovisual em si; a relevância dos estudos televisivos está unicamente na assimilação das imagens por parte do espectador; por as obras televisuais não terem um autor específico devem ser pormenorizadas.

Com a finalidade de explorar os aspectos estilísticos do produto aqui definido, partimos da proposta de Butler (2010), a quem se atribui a divisão do estudo de estilo em três dimensões: descritiva, analítica e avaliativa - explicadas por Rocha (2016, p. 28-34). A primeira consiste na desconstrução do produto televisivo, porque o mesmo trabalho utilizado na construção deve ser empregado. A segunda consiste em explorar qual é a função que o estilo desempenha nas cenas analisadas, uma vez que isso implica na suscitação de emoções do telespectador. A terceira, por fim, consiste na crítica acerca da estética do objeto, ainda que a intenção não seja classificá-lo como "bom" ou "ruim" numa escala baseada nas artes.

Neste exercício, o foco da análise está na primeira dimensão, de descrição do produto, uma vez que a proposta aqui é averiguar os indícios que podem classificar o programa do SBT como detentor das características da televisão clássica (classicaltelevision). Ademais, este trabalho, que equilibra informações oriundas da Literatura e do Cinema, adota os temos utilizados por ambas as áreas, além de se respaldar em suas teorias. Isso não significa aplicar um olhar literário ou cinematográfico para a televisão, numa intenção de igualar as mídias; ao contrário: faz-se um esforço para ampliar os estudos empíricos de televisão utilizando alguns conceitos já abordados por outras áreas. Acredita-se que, por meio da interdisciplinaridade, pode-se enriquecer o campo científico em questão.

\subsection{Descrição do produto}

Ao som de uma música festiva, aplausos, vibrações e encenações de entusiasmo, o início, com a câmera panorâmica - assumindo, neste trabalho, o vocabulário sobre análise de audiovisual também adotado por Pucci Jr. (2008) - em movimentação ondeada, frisa, em primeiro plano, cada participante, além de algumas pessoas da plateia. A câmera brinca com a mise-en-scène, e as personalidades, enquanto agentes da narrativa, brincam com a câmera. 


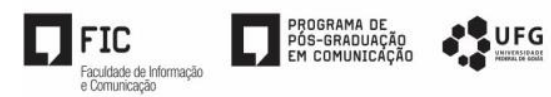

Estabelece-se um clima de game-show e assume-se a autoconsciência, isto é, "o grau de reconhecimento, pela narração, de sua veiculação ao espectador" (BORDWELL, 2005, p. 278).

Assim que a câmera se torna fixa, ela registra o apresentador frontalmente, em primeiro plano. Celso Portiolli, com sua camisa de manga três quartos e sorrindo entusiasticamente, pergunta ao público de casa se está com frio; numa tentativa de multiplicidade, compartilha a informação de que o inverno tem início naquele dia. Em diálogo com Calvino (1990), entendese a multiplicidade como a preocupação em atingir a intelectualidade de para quem se dirige, ou seja, transmitir novas informações ou conhecimentos gerais por meio da narrativa, fazendo com que o produto de entretenimento possa ser visto, sobretudo, como texto de informação, de onde o espectador poderá absorver certo conteúdo didático.

O prazer estilístico em sua fala ocorre a seguir, quando ele cria um trocadilho, dizendo que o programa "vai pegar fogo", sugerindo uma antítese provocativa de humor. Ressalta-se que trocadilho é a figura de construção que consiste na "utilização de palavras, abusando do seu sentido ambíguo" (HERGESEL, 2013, p. 70). No caso, "frio" e "inverno" são usados em seu sentido denotativo, mas "fogo" ganha uma conotação, o que, se relembrado o seu sentido denotativo, cria um jogo de palavras com a denotação apresentada previamente. Comenta-se, ainda, que antítese é a figura de pensamento responsável pela "aproximação de ideias opostas em elementos distintos" (HERGESEL, 2015, p. 157). No caso, "frio"/"inverno" e "fogo" são os elementos contrastantes.

Enquanto a turma de Carrossel é apresentada (pelo nome dos personagens da novela em vez do nome verdadeiro dos atores), o enquadramento ocorre em plano de meia figura. Celso inclui na sua fala a explicação de que, na última participação do elenco no quadro, o programa chegou se encerrou sem que eles conseguissem terminar as atividades e, por isso, retornaram desta vez, organizados para seguir até o fim. Enfatiza, também, que está ao vivo, reforçando a imagem trazida no canto inferior direito da tela, do logotipo da emissora com os dizeres indicadores de que a exibição estava acontecendo em tempo real.

Encerrada a parte inicial, utilizada unicamente para introduzir o quadro e situar o espectador, tem-se início o desenvolvimento, seguindo, de certa forma, a lógica aristotélica de condução de narrativas - mesmo, neste caso, tratando-se de uma não ficção. Segundo Evan S. Smith, uma história é composta por três seções: um início que introduza um conflito para a vida do personagem, marcando o lançamento da história; um meio que apresente as ações de desenvolvimento, uma série de revoluções e descobertas que conduzem a trama; e um fim que 
resolve os conflitos, muitas vezes com base em uma reversão na sortedo personagem principal (THOMPSON, 2003, p. 36).

Os participantes, então, competem entre si na Prova do Tato, cujo objetivo consiste em descobrir os objetos, tateando-os com os pés. Aqui já se mostra a relevância dos deadlines para o desenrolar da atração - as provas dependem da contagem regressiva ou da luta contra o tempo, o que suscita o sentimento de torcida. Deadline, neste trabalho, é entendido como o elemento narrativo que "demonstra a força da estrutura em definir a duração dramática como o tempo que se gasta para alcançar ou deixar de alcançar um objetivo" (BORDWELL, 2005, p. 280). Para Thompson (2003, p. 11), o uso de indicadores temporais é uma técnica que o cinema clássico e a televisão compartilham. Embora ambos os autores estejam se referindo ao cinema clássico hollywoodiano e à ficção televisiva, respectivamente, nota-se como esse artifício é eficaz para despertar a expectativa nos game-shows.

Durante a prova, enquanto os contrarregras - que atuam diante das câmeras, como assistentes de palco - organizam a brincadeira, Celso dirige-se para uma tenda posicionada num canto do estúdio. A câmera busca o objeto e, focalizando-o, cria-se um questionamento sobre o que haveria debaixo do tecido preto. Essa situação de suspense é retomada durante alguns momentos do programa, induzindo o interesse do espectador para uma matéria que estaria por vir e caracterizando a tenda como o motif dessa narrativa. Motif, para Thompson (2003, p. 25), é um elemento emblemático que levará à construção de uma ideia importante.

Situações que não interferem diretamente no eixo narrativo são constantes, suscitando a lembrança de que se trata de um programa de auditório. Em determinados momentos, por exemplo, o apresentador abre espaço para os artistas divulgarem seus trabalhos fora da emissora. Também é comum destinar beijos e abraços a quem está em casa - neste recorte, destaca-se o momento em que Portiolli declara seu amor a uma fã e diz que ela e o "pessoal da internet" (ou seja, os sbtistas, membros de fã-clubes criados por quem é apaixonado pela emissora) devem ser trazidos ao programa, porque ele gosta muito de todos.

Outras formas de interação com o público estão presentes, seja diretamente com a plateia, seja com o telespectador a distância. Durante a Prova do Paladar, por exemplo, Portiolli oferece o pudim utilizado na brincadeira para as moças do auditório; algumas moças são, inclusive, convidadas a participar da prova e pontuar para a equipe para a qual está torcendo. Já quem está em casa é convidado a participar de uma enquete, palpitando via SMS sobre qual será o time vencedor, além de poder usar a hashtag \#DomingoLegal no Twitter e esperar para ter seu perfil divulgado no gerador de caracteres. 


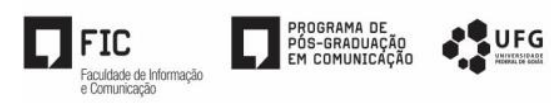

Um fato curioso sobre o Domingo Legal é a invasão do diretor na mise-en-scène, ainda que seja somente por meio de sua voz. Em determinados momentos, Portiolli pergunta a Magrão sobre o empenho dos participantes, sobre possíveis relações do motif com o quadro, sobre dúvidas a respeito da prova ou da pergunta - e é respondido com normalidade. O diretor, no entanto, não é a única figura off a participar da cena: uma auxiliar de limpeza é trazida ao palco e, enquanto limpa a sujeira resultada de uma prova, é focalizada pela câmera e pela fala do apresentador.

A presença de ganchos de diálogo - isto é, uma deixa no fim de um discurso para produzir o discurso seguinte (THOMPSON, 2003, p. 24) - também é evidente. Após o uso de carolinas pela Prova do Paladar, o apresentador aproveita os doces para contar a história de uma mãe que vende brigadeiros na rua para sustentar os filhos - e informa que ela e a família estarão no palco e terão surpresas. Em outro momento, Celso toma como base o nome de Konstantino, de origem grega, para anunciar que gravou matérias no exterior, em especial no Emirados Árabes, para serem veiculadas nos próximos programas.

Outras formas de gancho são os comentários que Portiolli faz sobre a participação dos atores em outros programas, elaborando, de certa forma, uma espécie de propaganda para os outros produtos da emissora. Quando Nicholas Torres vai participar de uma das provas, por exemplo, o apresentador diz que o viu no Programa Eliana e pede uma demonstração de seu talento como cantor. Após uma breve cantoria, Portiolli aproveita o tema "música" para avisar que o cantor Biel estará no programa - notícia à qual o auditório é convidado a reagir com euforia.

Gancho maior, contudo, ocorre com as idas aos comerciais e merchandisings. A fim de manter a audiência ligada no programa, os intervalos só entram após o informe de uma prova a ser realizada e antes de sua realização - ou seja, é necessário aguardar a volta dos anúncios publicitários para saber se a equipe obteve êxito na execução da atividade. Quando é necessário, no entanto, encontrar uma forma de preencher a narrativa enquanto se aguarda a preparação de uma prova, surgem informações aleatórias, como o provável tratamento de beleza feito pela assistente de palco Diana, que é trazida em primeiro plano para agradecer o elogio.

Voltando à linha de enredo principal, após a Prova do Paladar, é anunciada a Prova do Bicho, na qual o participante tateia, com as mãos, brinquedos de pelúcia para adivinhar que animal é. Surge, pela primeira vez, uma câmera alta para registrar alguns momentos da prova. Os enquadramentos, por sua vez, não são muito experimentais: no jogo de perguntas e respostas, predomina o plano de meia figura, com foco no apresentador quando do enunciado 


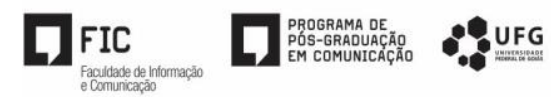

e na equipe quando da resposta. Se a resposta é acertada, outrossim, geralmente entra uma canção relacionada ao tema da pergunta.

Entre uma determinada pergunta e outra, Portiolli paralisa a fábula da micronarrativa para antecipar o quadro (ou micronarrativa) seguinte: a senhora que vende brigadeiros. Enquanto ele fala, a tela é dividida ao meio: de um lado, é exibido um print screen da matéria veiculada pelo portal da revista Veja SP; do outro, a assistente de palco Diana aparece carregando uma forma de brigadeiro, com plano detalhe nos doces. O motif é retomado, e o diretor revela que, debaixo da tenda, há algo relacionado com a história da tal família.

Mais adiante na narrativa, uma vinheta sonora invade a mise-en-scène. Com os dizeres “Domingo, Domingo, Domingo Legal”, esse leitmotiv - recurso estilístico que se caracteriza por uma significação especial que, quando inserido no decurso de uma narração, remete a memória do espectador a um determinado tema - comunica que o programa atingiu a liderança de audiência no IBOPE; a vinheta, por já ter sido presente em outras edições do programa,é eficaz para sinalizar o primeiro lugar de audiência. Para comemorar com descontração, Celso convida Ana Luiza - garota que ficou famosa após participar do Programa Silvio Santos e conquistar o público com sua risada indiscreta - para uma competição de risos. O ator Nicholas Torres, que demonstra saber imitá-la, junta-se ao momento, que é enfatizado pela sonoplastia (com áudio de risadas gravadas).

Logo em seguida, Portiolli diz que, para aproveitar que há muita criança assistindo ao programa, trará ao palco o novo fenômeno do funk. Biel entra cantando, acompanhando pelo balé feminino da emissora. A câmera panorâmica registra a dança dos que estão em cena, executando movimentos horizontais de ondulação, ora em angulação alta, ora em angulação baixa, ora de maneira frontal. Nota-se, neste ponto, um paradoxo - figura de pensamento na qual "conciliam-se duas ideias opostas de modo a contrariar o senso comum" (HENRIQUES, 2011, p. 149) - entre o discurso do apresentador e a música apresentada: ao passo que Celso justifica a presença de Biel por causa da audiência do público infantil, o cantor performa a música Boquinha.

Justifica-se: essa é uma música que faz referência ao sexo oral. Excerto da letra: "Me usa, vem e se lambuza / Me beija, vem cá e abusa / Descendo pelo pescoço / Vem tirando a minha blusa / Adoro essa mão boba / Ousadia rolando solta / Se eu puxo o cabelo dela / A gatinha já vira loba / Adoro quando passa a unha / Me deixa arranhado, todo arrepiado / Me amarro quando ela se sussurra / 'Hoje fica tranquilo que eu faço trabalho' / Começa beijando 
minha orelha / Já me provocando, falando gracinha / Enquanto ela se ajoelha / Já se preparando com aquela carinha""12.

Após a apresentação, Celso pergunta ao auditório se alguém deseja fazer alguma pergunta a Biel. Uma menina da torcida do time amarelo se manifesta, pedindo uma foto, e o cantor se dispõe a participar de uma selfie em conjunto com aquela parte do auditório. Uma das garotas, então, inusitadamente, aproveita a distração de Biel e o beija na boca - o que vira motivo de piada para o apresentador, que agradece a participação do garoto no programa e elogia seu desempenho no quadro A Princesa e o Plebeu.

Para retomar a linha de enredo principal, é feita uma nova apresentação dos participantes, que se enfrentarão no Torta na Cara - momento em que uma pergunta é feita a um participante de cada equipe e quem responder primeiro de maneira correta tem o direito de lambuzar o rosto do adversário. O fenômeno ocorre várias vezes (sempre entre duplas, sendo um de cada equipe), mantendo o mesmo método -ouvir a pergunta, bater no botão, responder corretamente e sujar o oponente. Cria-se, assim, uma paradiástole - figura de construção que "alinha segmentos com a mesma sintaxe, o mesmo ritmo e o mesmo comprimento" (SUHAMY, 1994, p. 85) - no audiovisual.

Nessa nova brincadeira, entre uma determinada pergunta e outra, Celso chama um videotape gravado por Patrícia Abravanel, no qual ela faz propaganda do programa Máquina da Fama e anuncia duas novidades: o quadro Desafio da Máquina e as edições especiais do Máquina da Fama de Férias. Novamente, firma-se o vínculo entre os vários produtos da emissora, percebido também quando Portiolli comenta como seu perfume da Jequiti (empresa de cosméticos do Grupo Silvio Santos) é agradável e vale a pena ser adquirido.

Quando a brincadeira das tortas chega ao fim, é anunciada a Gincana Final, na qual cada um dos times tem que passar por seis provas consecutivas e tentar concluir o percurso no menor tempo possível para poder dobrar a pontuação que tem no placar. O time amarelo é o primeiro a realizar o desafio, acompanhado por recursos estilísticos já vistos durante o programa: música festiva intercalando-se à melodia de suspense, locução por parte do apresentador, cronômetro na tela, câmera em constante movimentação. Acredita-se que todos esses elementos, em conjunto, contribuem para o dinamismo da brincadeira.

O resultado da enquete anunciada no início do programa aparece na tela somente após o primeiro minuto de realização da gincana pelo time azul: pelos números, a equipe amarela

\footnotetext{
${ }^{12}$ Boquinha (Biel). Vagalume. Disponível em: 〈http://www.vagalume.com.br/biel/boquinha.html>. Acesso em: 12 abr. 2016.
}

Comun. \& Inf., Goiânia, GO, v. 20, n. 3, p.113-131, out./dez. 2017 
tem 59,28\% de preferência do público contra 40,72\% da equipe azul. Contrariando a expectativa dos espectadores, a equipe azul realiza todas as provas em 7 minutos e 18 segundos (contra 8 minutos e uma prova incompleta da equipe amarela) e sai vitoriosa com 2100 pontos - contra 1750 dos adversários.

\section{APONTAMENTOS FINAIS}

A bagunça é a emoção assumida logo nos primeiros minutos do programa, quando o movimento de câmera faz um registro aparentemente sem preocupação de trajeto a ser percorrido e quando o apresentador revela a possível desorganização de um programa anterior que chegou ao fim sem desfecho para a narrativa. Essa liberdade no modo de condução dos enredos é uma característica do estilo despojado do SBT, que frequentemente é lembrada por ser "a TV mais feliz do Brasil", mesmo já tendo reformulado seu slogan.

A cumplicidade entre os programas do SBT também fica evidente, desde a participação de uma telenovela da emissora no dominical até as incursões de chamadas e comentários (como o videotape anunciando o Máquina da Fama e o reconhecimento de Celso sobre o que acontece no Programa Eliana). Isso fortalece a sensação de que o SBT é uma grande família, com todos convivendo com todos - premissa reforçada pela permissão que é dada tanto ao diretor quanto à auxiliar de limpeza para entrarem na cena.

Ainda que o produto não se caracterize como ficção televisiva, a demarcação aristotélica de estruturação narrativa é visível: têm-se a introdução (segundos iniciais de apresentação dos participantes e de boas-vindas ao espectador), o desenvolvimento (jogos, perguntas, provas, tortadas) e o desfecho (gincana final). A apropriação de outras estratégias da narração clássica, sobretudo no que confere ao estilo do cinema hollywoodiano - como ganchos de diálogo, motifs e deadlines -, ressalta a força comunicativa desses elementos também na televisão.

Por fim, infere-se que o programa Domingo Legal, embora sustente em seu conteúdo formatos antigos, faz adequações de acordo com o contexto da época em que é veiculado, evitando que o produto se torne ultrapassado. Percebe-se, ainda, a despreocupação do trabalho linguístico visando às nuances poéticas, vista a escassez de figuras de linguagem (sejam verbais, sejam visuais); essa ausência, no entanto, é condizente com sua intenção estética: a demarcação da espontaneidade e a desconstrução de um padrão fixo que pode levar ao engessamento.

Já a sonoridade festiva, a movimentação de câmeras, os enquadramentos, dentre tantas artimanhas da parte técnica são apenas uma parcela do estilo que se consolida com o suporte de 
diversos elementos da narração. A vivacidade na narrativa, por fim, é alimentada pela animação oriunda do auditório, pelos diálogos aparentemente improvisados do apresentador, pela energia dispensada pelos participantes e pela possibilidade de participação de quem está em casa, ainda que de forma tímida.

\section{REFERÊNCIAS}

BALLY, Charles. Traité de stylistique française. Paris: Klincksieck, 1909.

BECHARA, Evanildo. Moderna gramática portuguesa. 37. ed. Rio de Janeiro: Nova Fronteira, 2009.

BORDWELL, David. O cinema clássico hollywoodiano: normas e princípios narrativos. In: RAMOS, Fernão Pessoa (Org.). Teoria contemporânea do cinema. São Paulo: Senac, 2005, v. 2, p. 277-301. 2013.

Sobre a História do Estilo Cinematográfico. Campinas (SP): Editora da Unicamp,

BUTLER, Jeremy G. Notes on the Soap Opera Apparatus: Televisual Style and "As the World Turns". Cinema Journal, ed.25, n. 3, p. 53-70, 1986.

Television style. Nova Iorque: Routledge, 2010.

CALVINO, Italo. Seis propostas para o próximo milênio: lições americanas. São Paulo: Companhia das Letras, 1990.

CASTRO, Daniel. Silvio Santos desiste de Fantasia e pode exibir séries aos domingos. Notícias da TV, 16 dez. 2016. Disponível em: 〈https://goo.gl/e7I84j>. Acesso em: 21 dez. 2016.

FALCHETI, Fabrício. Roberto Manzoni pede período sabático e deixa direção de programas no SBT. NaTelinha, 26 abr. 2016. Disponível em: <https://goo.gl/mQgynd>. Acesso em: 09 dez. 2016.

DOMINGO Legal. O Programa. SBT. 2016. Disponível em: 〈https://goo.gl/m2AaZN〉. Acesso em: 21 dez. 2016.

FOLHA Online. Justiça mantém suspensão do programa "Domingo Legal". Folha de São Paulo, 21 set. 2003. Disponível em: 〈https://goo.gl/KaDjFw>. Acesso em: 21 dez. 2016.

GUIRAUD, Pierre. A estilística. São Paulo: Mestre Jou, 1970.

HENRIQUES, Claudio Cezar. Estilística e discurso: estudos produtivos sobre texto e expressividade. Rio de Janeiro: Elsevier, 2011.

HERGESEL, João Paulo. Estilística cibernética. Guaratinguetá: Penalux, 2013. 
HERGESEL, João Paulo. Estilística aplicada à websérie. Saarbrücken (Alemanha): Novas Edições Acadêmicas, 2015.

LOTMAN, Iuri. La retórica <Traducción>. Escritos, Revista del Centro de Ciencias del Lenguaje, Puebla, Pue (México), n. 9, jan./dec. 1993, p. 21-46. Disponível em: <https://goo.gl/Oqxs0c>. Acesso em: $21 \mathrm{dez} .2016$.

MANZONI, Roberto. Os bastidores da televisão brasileira. Osasco: Novo Século, 2005.

MARTINS, Nilce Sant'Anna. Introdução à estilística: a expressividade na língua portuguesa. 4. ed. São Paulo: Edusp, 2008.

MATTOS, Laura. Em queda desde caso PCC, Gugu tenta subir ibope com jornalismo. FNDC - Fórum Nacional pela Democratização da Comunicação, 24 jan. 2007. Disponível em: <https://goo.gl/9td0nl>. Acesso em: 21 dez. 2016.

MONTEIRO, José Lemos. A estilística: manual de análise e criação do estilo literário. Petrópolis: Vozes, 2005.

PECCOLI, Vitor. "Domingo Legal" marca ótima audiência e incomoda a Globo. TV Foco, 18 maio 2015a. Disponível em: <https://goo.gl/2TqTzg>. Acesso em: 21 dez. 2016.

. "Domingo Legal" marca ótima audiência e alcança a liderança. TV Foco, 22 jun. 2015b. Disponível em: <https://goo.gl/1brYNe>. Acesso em: 21 dez. 2016.

PUCCI JR., Renato Luiz. Vocabulário. In: neon-realismo. Porto Alegre: Sulina, 2008, p. 269-271.

Inovações estilísticas na telenovela: a situação em Avenida Brasil. Revista FAMECOS, Porto Alegre, v. 21, n. 2, p. 675-697, maio-ago. 2014a. Disponível em: <https://goo.gl/5CsLQC>. Acesso em: $21 \mathrm{dez} .2016$.

Sobre a história do estilo cinematográfico (Resenha). REBECA: Revista Brasileira de Estudos de Cinema e Audiovisual, São Paulo, ano 3, ed. 5, p. 1-6, jan./jun. 2014b. Disponível em: 〈http://goo.gl/KmC37C〉. Acesso em: 21 dez. 2016.

REVISTA da TV. 'Mundo Disney' prejudica a audiência do 'Domingo Legal'. Bastidores da TV, 15 out. 2015. Disponível em: 〈https://goo.gl/0yIAVy>. Acesso em: 21 dez. 2016.

RICCO, Flávio. SBT decide acabar com "Domingo Legal”; Portiolli irá para sábado à tarde. UOL TV e Famosos, 7 dez. 2016. Disponível em: <https://goo.gl/Tu4aMI>. Acesso em: 21 dez. 2016.

ROCHA, Simone Maria. O estilo televisivo e sua pertinência para a TV como prática cultural. Revista FAMECOS, Porto Alegre, v. 21, n. 3, p. 1082-1099, set.-dez. 2014. Disponível em: <https://goo.gl/4LeWTl>. Acesso em: 21 dez. 2016.

O estilo televisivo :e sua pertinência para a TV como prática cultural. Florianópolis: Insular, 2016. 
SANTOS, Renan. "Lembra Dessa?" "Domingo Legal" faz cobertura da morte dos Mamonas Assassinas em 1996. TV Foco, 23 ago. 2014. Disponível em: 〈https://goo.gl/cqQoeH〉. Acesso em: 21 dez. 2016.

SBT. International Sales. 2016. Disponível em: <https://goo.gl/h2TuK1>. Acesso em: 21 dez. 2016.

SILVA, Míriam Cristina Carlos. A pele palpável da palavra: a comunicação erótica em Oswald de Andrade. Sorocaba: Provocare, 2009.

SUHAMY, Henri. As figuras de estilo. Porto (Portugal): Rés, 1994.

THOMPSON, Kristin. Storytelling in film and television. Cambridge; Londres: Harvard University Press, 2003. 